\title{
Comparative in Vitro Efficacy Assessment Methods of a Bioagent Trichoderma harzianum THR 4 against Rice Blast Pathogen Magnaporthe oryzae oryzae
}

\author{
Z. Nazifa, F. M. Aminuzzaman* (), L. Laila, M. L. Ashrafi \\ Department of Plant Pathology, Faculty of Agriculture, Sher-e-Bangla Agricultural University, Sher-e-Bangla Nagar, Dhaka, \\ Bangladesh \\ Email: *aminsaupp@yahoo.com
}

How to cite this paper: Nazifa, Z., Aminuzzaman, F.M., Laila, L. and Ashrafi, M.L. (2021) Comparative in Vitro Efficacy Assessment Methods of a Bioagent Trichoderma harzianum THR 4 against Rice Blast Pathogen Magnaporthe oryzae oryzae. Open Access Library Journal, 8: e7510.

https://doi.org/10.4236/oalib.1107510

Received: May 10, 2021

Accepted: November 29, 2021

Published: December 2, 2021

Copyright $\odot 2021$ by author(s) and Open Access Library Inc.

This work is licensed under the Creative Commons Attribution International License (CC BY 4.0).

http://creativecommons.org/licenses/by/4.0/

(c) (i) Open Access

\begin{abstract}
Rice is the staple food crop for a large part of the human population in the world today. Rice blast is by far the most important disease of the many diseases that attack rice caused by Magnaporthe oryzae oryzae $(\mathrm{MoO})$. Failures of entire rice crops have resulted directly from rice blast epidemics. Trichoderma harzianum the well-known antagonistic fungus is widely used in agriculture as bio-fungicide. In the present study five different designs of in vitro dual culture techniques were evaluated on Potato Dextrose Agar (PDA) to find out the most suitable technique to interaction study between MoO and T. harzianum THR 4. The design where four $5.0 \mathrm{~mm}$ mycelia discs of T. harzianum THR 4 were set on the periphery of the petridish surrounding one disc of MoO on the center of the petridish in dual culture gave most satisfactory result with $92 \%$ growth inhibition of $\mathrm{MoO}$ in compare to control plate of MoO.
\end{abstract}

\section{Subject Areas \\ Agricultural Science}

\section{Keywords}

Rice Blast, Magnaporthe oryzae oryzae (MoO), Trichoderma harzianum THR 4, Biological Control

\section{Introduction}

Rice (Oryza sativa L.) is a staple food for half of the world's population [1]. It is 
central to Bangladesh's economy, accounting for nearly 20 percent of gross domestic product (GDP) and providing about one-sixth of the national income of Bangladesh [2]. Rice blast caused by Magnaporthe oryzae oryzae (MoO) is a key concern in combating global food insecurity given the disease is responsible for approximately $30 \%$ of rice production losses globally the equivalent of feeding 60 million people [3]. These losses increase the global rice price and reduce consumer welfare and food security. As rice is the staple crop for more than half the world's population so any reduction in rice blast would have substantial beneficial effects on consumer livelihoods. Pyricularia oryzae (Po) isolated from infected leaf and panicle and identified based on cultural characteristics and conidia morphology and mycelia growth of Pyricularia isolates varied significantly with fair to excellent sporulation ability [4].

Chemicals are commonly applied for controlling rice blast disease [5] [6] [7]. However, the frequent use of fungicides on crops may cause hazards to human beings, plant health, beneficial micro-organisms, and develop fungicide resistance into the pathogens and residual toxicity in plant parts. On the other hand, some bio-control agents have proved to be most secure and have no adverse impact on environment [8] [9]. Eight botanical plant extracts have been tested in vitro against Magnaporthe oryzae oryzae and found satisfactory reduction in mycelia growth of MoO [10]. Trichoderma spp., the well-known antagonistic fungi are widely used in agriculture as bio-fungicides [11]. Trichoderma spp., inhibited the mycelia growth of rice blast fungus [12]. The use of antagonistic fungi to control the destructive plant pathogens is getting more importance since few decades [13] [14].

Bio-control agents are widely regarded as natural remedy with non-threatening affect. Trichoderma species act against target organisms in several ways [15]. Volatile and non-volatile compounds of Trichoderma spp. were analysed by GC-MS technique (Gas chromatography-mass spectrometry (GC-MS), an analytical method that combines the features of gas-chromatography and mass spectrometry to identify different substances within a test sample [16]. Time of the application of the Trichoderma is also important. The purpose of this study was to evaluate comparative efficacy assessment methods of bio-agent Trichoderma harzianum in controlling Magnaporthe oryzae oryzae (MoO) in vitro.

\section{Materials and Methods}

\subsection{Materials}

\subsubsection{Experimental Site}

The experiment was conducted in the Laboratory, Department of Plant Pathology, Sher-e-Bangla Agricultural University, Dhaka.

\subsubsection{Experimental Period}

The experiment was conducted during the period from June 2018 to December 2019. 


\subsubsection{Inoculum of Test Fungus M. oryzae oryzae (MoO)}

The present study was conducted to evaluate the efficacy assessment methods of T. harzianum THR 4 against a virulent isolate of Magnaporthe oryzae oryzae MoO19 [17]. The isolate was identified based on three celled pyriform conidia (Figure 1).

\subsubsection{Inoculum of antagonist $T$. harzianum THR4}

The bio-control agent $T$. harzianum THR 4 was obtained from Pathology Laboratory, Department of Plant Pathology, Sher-e-Bangla Agricultural University, Dhaka [18]. T. harzianum was sub-cultured in in vitro condition for antagonism test against $\mathrm{MoO}$ (Figure 2 and Figure 3 ).

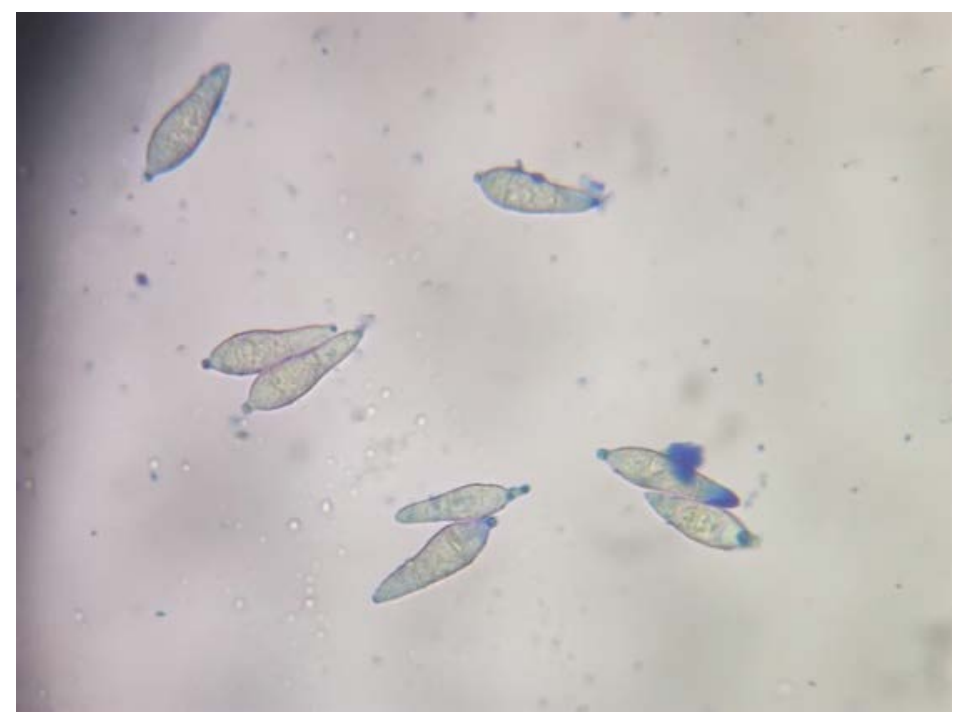

Figure 1 . Three celled pyriform conidia of $\mathrm{MoO}(\times 40)$.

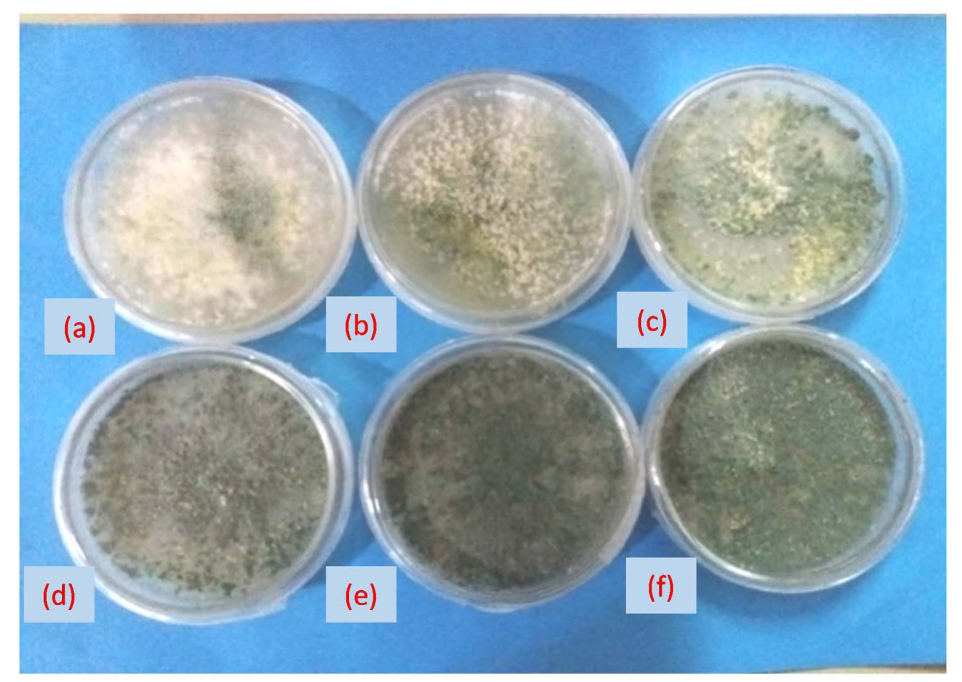

Figure 2. Pure culture of Trichoderma harzianum THR 4 at different days after inoculation; (a) Mycelial growth at 6DAI; (b) Mycelial growth at 7DAI; (c) Mycelial growth at 8DAI; (d) Mycelial growth at 10DAI; (e) Mycelial growth at 12DAI; (f) Mycelia growth at 14DAI. 


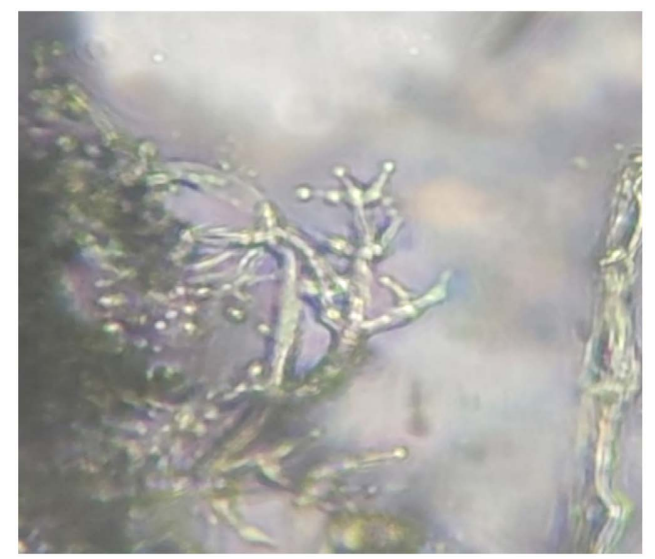

Figure 3. Mycelia, conidiophores, phialides and conidia of T. harzianum THR $4(\times 40)$.

\subsection{Materials}

\subsubsection{Efficacy of Bio-Agent T. harzianum THR 4 in Controlling Radial Mycelia Growth of MoO in Vitro}

Bio-control agent such as T. harzianum was tested under laboratory conditions against rice blast causing fungus, $\mathrm{MoO}$. This experiment was done to evaluate $T$. harzianum against $\mathrm{MoO}$ following different methods in dual culture on PDA plates.

Four mm disc of test fungus and biocontrol agent at 2DAI (Figure 4) were placed at opposite sides to each other in Petri dishes in five different designs that containing sterilized PDA medium. There were 3 replications of each design containing bio-control agent and Magnaporthe oryzae oryzae and were incubated at $25^{\circ} \mathrm{C}$. Petri dishes containing the test fungus and bio-control agents separately incubated at $30^{\circ} \mathrm{C}$ served as control. Colony diameter of both bio-control agent and the test fungus were recorded after each 48 hours by giving straight line in the center of both colonies with permanent marker. The interaction and mechanism of antagonism was observed when the colonies of both fungi met [19].

\subsubsection{Designs of Dual Culture Technique for Observing the Efficiency of T. harzianum against $\mathrm{MoO}$}

This experiment was done following five different designs of dual culture technique to know the interactions among $\mathrm{MoO}$ and Trichoderma harzianum THR 4 and also control plates were set.

In first design, one disc of $\mathrm{MoO}$ was set against one disc of T. harzianum following dual culture technique. In second design, three discs of $T$. harzianum were set on the periphery of the petridish surrounding one disc of $\mathrm{MoO}$ on the center of the petridish following dual culture technique. In third design, four discs of $T$. harzianum were set on the periphery of the petridish surrounding one disc of $\mathrm{MoO}$ on the center of the petridish following dual culture technique. In fourth design, three discs of $\mathrm{MoO}$ were set on the periphery of the petridish surrounding one disc of $T$. harzianum on the center of the petridish following dual culture technique. In fifth design, four discs of $\mathrm{MoO}$ were set on the periphery of 


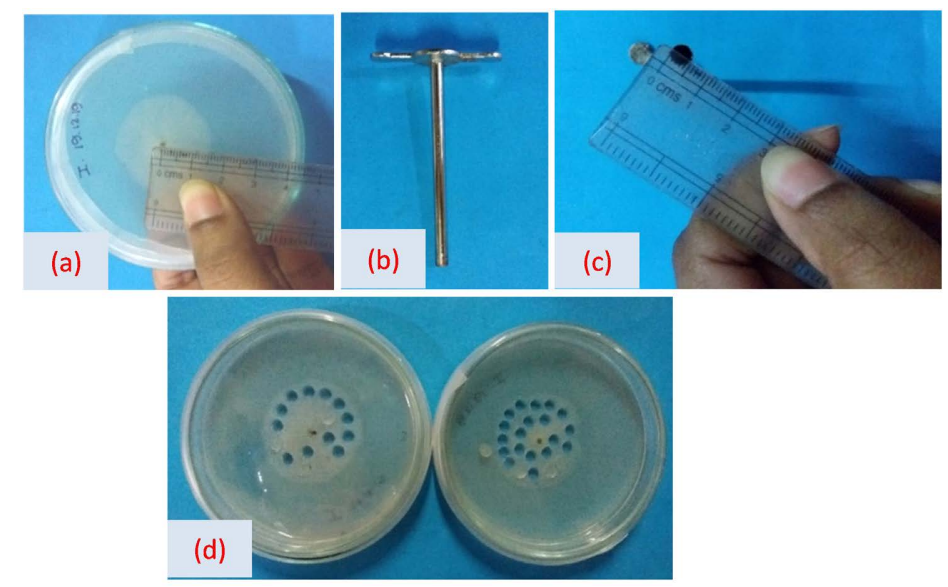

Figure 4. (a) Measuring the radial growth of THR 4 at 2DAI; (b) Block cutter; (c) Measuring the diameter of mycelial block; (d) After removing the blocks from cultured plate of T. harziamum THR 4.

the petridish surrounding one disc of $T$. harzianum on the center of the petridish following dual culture technique. There was also two different petridish set as control condition for both tested fungus $\mathrm{MoO}$ and bio-agent Trichoderma harzianum (Figure 5).

\subsubsection{Experimental Design and Statistical Analysis}

The experiment was done following Complete Randomized Design (CRD) with three replications and statistical analysis was done using Statistix10 software. Data were analyzed at 5\% level of significance. One factor analysis of variance (ANOVA) was done and critical value for comparison was recorded as LSD value. There are different groups ( $a, b$, etc.) in which the means are not significantly different from one another. Data are significantly different from one group to another.

\section{Result}

\subsection{In Vitro Mycelia Radial Growth of MoO with Bio-Agent Trichoderma harzianum THR 4 in PDA}

Third design where four discs of $T$. harzianum were set on the periphery of the petridish surrounding one disc of $\mathrm{MoO}$ on the center of the petridish following dual culture technique successfully inhibited the fungal growth and infection of $\mathrm{MoO}(2 \mathrm{~mm})$ whereas the growth of bio-agent was $16.67 \mathrm{~mm}$ followed by second design where three discs of $T$. harzianum were set on the periphery of the petridish surrounding one disc of $\mathrm{MoO}$ on the center of the petridish inhibited the fungal growth $(4.33 \mathrm{~mm})$ whereas the growth of bio-agent was $18.33 \mathrm{~mm}$ at 6DAI (Table 1). In fourth and fifth design mycelia radial growth of $\mathrm{MoO}$ was $6.67 \mathrm{~mm}$ whereas the mycelia growth of bio-agent was $33.33 \mathrm{~mm}$ followed by first design where mycelia radial growth of $\mathrm{MoO}$ was $11.67 \mathrm{~mm}$ whereas mycelia radial growth of $T$. harzianum recorded $28.33 \mathrm{~mm}$. In control condition mycelia radial growth of tested fungus and bio-agent was $25 \mathrm{~mm}$ and $40 \mathrm{~mm}$ respectively. 


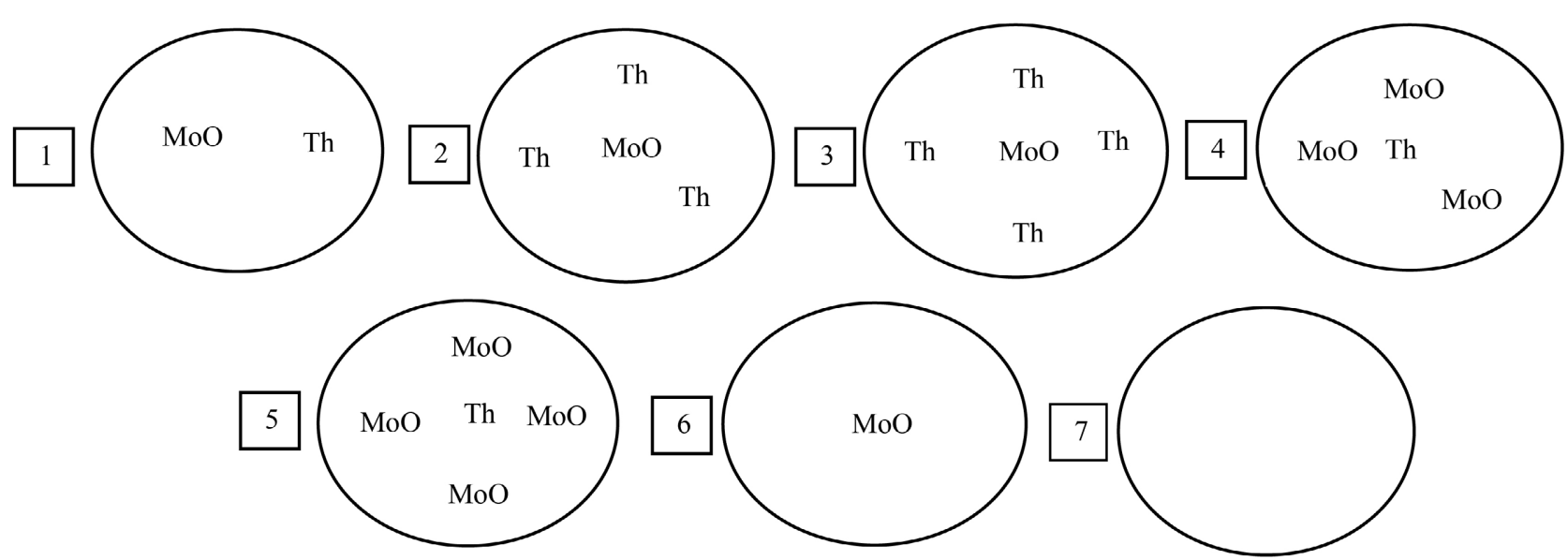

Figure 5. Five treatment and two control designs to interaction study between T. harzianum THR 4 and MoO. MoO denotes Magnaporthe oryzae oryzae and Th denotes T. harzianum THR 4.

Table 1. Mycelia radial growth inhibition of $\mathrm{MoO}$ and T. harzianum THR 4 by each other in different in vitro treatment design in PDA.

\begin{tabular}{|c|c|c|c|c|}
\hline Treatment Design & $\begin{array}{l}\text { Mycelia radial } \\
\text { growth of } \\
\text { MoO }(\mathrm{mm})\end{array}$ & $\begin{array}{l}\text { \% Inhibition } \\
\text { of growth }\end{array}$ & $\begin{array}{l}\text { Mycelia radial } \\
\text { growth of Th } \\
(\mathrm{mm})\end{array}$ & $\begin{array}{l}\% \text { Inhibition } \\
\text { of growth }\end{array}$ \\
\hline 1. MoO and Th disks were set in the opposite periphery. & $11.67 \mathrm{~b}$ & 53.32 & $28.33 \mathrm{c}$ & 29.18 \\
\hline $\begin{array}{l}\text { 2. MoO disk in the center and three Th disks on the } \\
\text { periphery of the dish in equal distance }\end{array}$ & $4.33 \mathrm{~d}$ & 82.68 & $18.33 \mathrm{~d}$ & 54.18 \\
\hline $\begin{array}{l}\text { 3. MoO disk in the center and four Th disks on the } \\
\text { periphery of the dish in equal distance }\end{array}$ & $2.00 \mathrm{e}$ & 92.00 & $16.67 \mathrm{~d}$ & 58.33 \\
\hline $\begin{array}{l}\text { 4. Th disk in the center and three } \mathrm{MoO} \text { on the periphery } \\
\text { of the petridish in equal distance }\end{array}$ & $6.67 c$ & 73.32 & $33.33 \mathrm{~b}$ & 16.68 \\
\hline $\begin{array}{l}\text { 5. Th disk in the center and four discs of } \mathrm{MoO} \text { on the } \\
\text { periphery of the petridish in equal distance }\end{array}$ & $6.67 c$ & 73.32 & $33.33 \mathrm{~b}$ & 16.68 \\
\hline 6. Control condition for $\mathrm{MoO}$ & $25.00 \mathrm{a}$ & 0.00 & - & - \\
\hline 7. Control condition for Th & - & - & $40.00 \mathrm{a}$ & 0.00 \\
\hline $\operatorname{LSD}(0.05)$ & 1.83 & & 2.26 & \\
\hline
\end{tabular}

$\mathrm{MoO}=$ Magnaporthe oryzae oryzae and $\mathrm{Th}=$ Trichoderma harzianum THR 4.

In in vitro condition third design where four discs of $T$. harzianum were set on the periphery of the petridish surrounding one disc of $\mathrm{MoO}$ on the center of the petridish following dual culture technique gave most satisfactory result with 92\% growth inhibition of $\mathrm{MoO}$ in compare to control treatment (Figure 6).

\subsection{Interaction between MoO and Trichoderma harzianum THR 4 in Dual Culture Designs}

Data were recorded to understand the interactions between tested fungus $\mathrm{MoO}$ and bio-agent Trichoderma harzianum THR 4 . The third design where four discs 


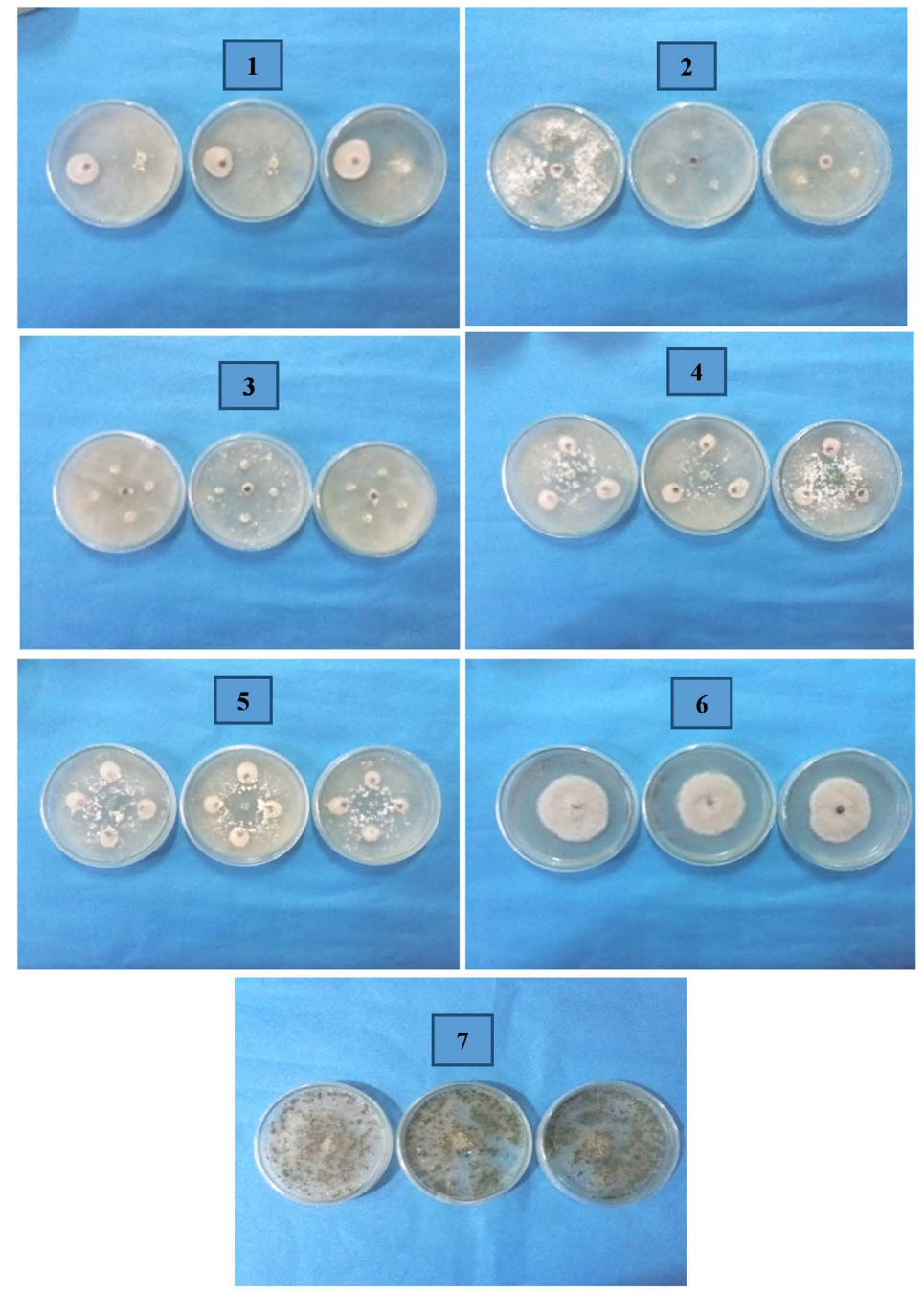

Figure 6. Growth of Magnaporthe oryzae oryzae (MoO) and Trichoderma harzianum (Th) in both dual culture technique and in control condition in PDA at 6 DAI; $1=$ One disc of MoO was set against one disc of Th, 2 = Three discs of Th were set on the periphery of the petridish surrounding one disc of $\mathrm{MoO}$ on the center of the petridish, $3=$ Four discs of Th were set on the periphery of the petridish surrounding one disc of $\mathrm{MoO}$ on the center of the petridish, $4=$ Three discs of $\mathrm{MoO}$ were set on the periphery of the petridish surrounding one disc of Thon the center of the petridish, $5=$ Four discs of MoO were set on the periphery of the petridish surrounding one disc of Thon the center of the petridish and $6=$ Control plates of $\mathrm{MoO}$ and $7=$ Control plates of Th.

of $T$. harzianum were set on the periphery of the petridish surrounding one disc of $\mathrm{MoO}$ on the center of the petridish following dual culture technique successfully inhibited the fungal growth and infection of $\mathrm{MoO}$ towards bio-agent was $2 \mathrm{~mm}$ whereas the growth of bio-agent towards the tested fungus was $15 \mathrm{~mm}$ followed by second design where three discs of T. harzianum were set on the periphery of the petridish surrounding one disc of $\mathrm{MoO}$ on the center of the petridish inhibited the fungal growth $(4 \mathrm{~mm})$ towards bio-agent whereas the growth of bio-agent towards tested pathogen was $18 \mathrm{~mm}$ at 6DAI (Table 2 and Figure 7). In fourth design mycelia radial growth of MoO towards T. harzianum was 
Table 2. Interaction of Magnaporthe oryzae oryzae (MoO) with Trichoderma harzianum THR 4 (Th) in dual culture designs in PDA at 6 DAI.

\begin{tabular}{|c|c|c|c|c|}
\hline Treatment Design & $\begin{array}{c}\text { Mycelia radial } \\
\text { growth of MoO } \\
\text { towards Th at } 6 \\
\text { DAI }(\mathrm{mm})\end{array}$ & $\begin{array}{l}\text { \% Inhibition } \\
\text { of MoO } \\
\text { growth in } 6 \\
\text { DAI }\end{array}$ & $\begin{array}{l}\text { Mycelia radial } \\
\text { growth of } \mathrm{Th} \\
\text { towards } \mathrm{MoO} \\
\text { at } 6 \mathrm{DAI}(\mathrm{mm})\end{array}$ & $\begin{array}{l}\% \text { Inhibition } \\
\text { of Th growth } \\
\text { in } 6 \text { DAI }\end{array}$ \\
\hline 1. MoO and Th disks were set in the opposite periphery & $8.33 \mathrm{~b}$ & 66.68 & $28.33 \mathrm{c}$ & 29.17 \\
\hline $\begin{array}{l}\text { 2. MoO disk in the center and three Th disks on the } \\
\text { periphery of the dish in equal distance }\end{array}$ & $4.00 \mathrm{~cd}$ & 84.00 & $18.00 \mathrm{~d}$ & 55.00 \\
\hline $\begin{array}{l}\text { 3. MoO disk in the center and four Th disks on the } \\
\text { periphery of the dish in equal distance }\end{array}$ & $2.00 \mathrm{~d}$ & 92.00 & $15.00 \mathrm{e}$ & 62.50 \\
\hline $\begin{array}{l}\text { 4. Th disk in the center and three } \mathrm{MoO} \text { on the periphery } \\
\text { of the petridish in equal distance }\end{array}$ & $4.67 \mathrm{c}$ & 81.32 & $35.33 \mathrm{~b}$ & 11.67 \\
\hline $\begin{array}{l}\text { 5. Th disk in the center and four discs of } \mathrm{MoO} \text { on the } \\
\text { periphery of the petridish in equal distance }\end{array}$ & $5.00 \mathrm{c}$ & 80.00 & $35.00 \mathrm{~b}$ & 12.50 \\
\hline 6. Control condition for $\mathrm{MoO}$ & $25.00 \mathrm{a}$ & 0.00 & - & - \\
\hline 7. Control condition for Th & - & - & $40.00 \mathrm{a}$ & 0.00 \\
\hline $\operatorname{LSD}(0.05)$ & 2.26 & & 2.26 & \\
\hline
\end{tabular}

$\mathrm{MoO}=$ Magnaporthe oryzae oryzae and Th = Trichoderma harzianum THR 4.

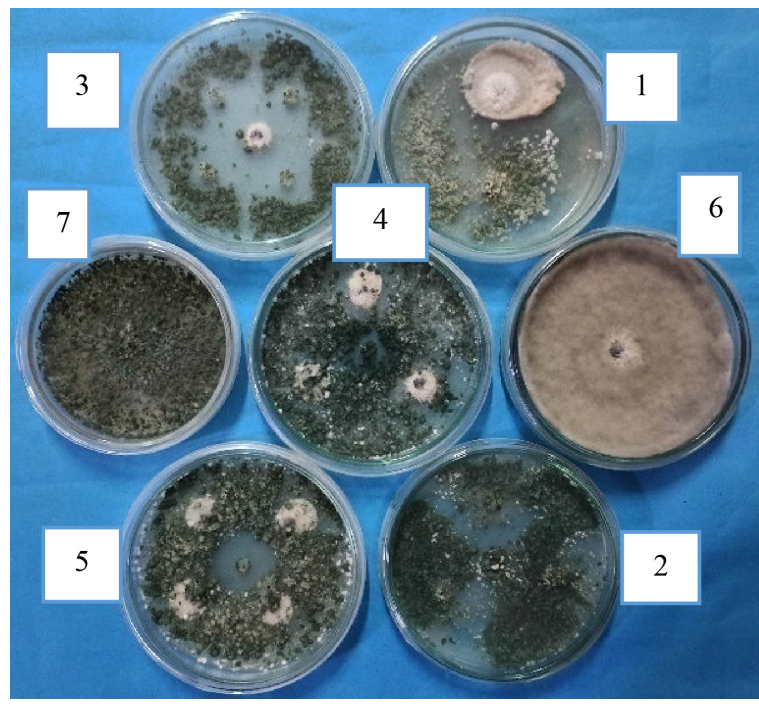

Figure 7. Growth of Magnaporthe oryzae oryzae (MoO) and bio-agent Trichoderma harzianum THR $4(\mathrm{Th})$ in dual culture and control condition on PDA; $1=$ One disc of MoO was set against one disc of $T$. harzianum, 2 = Three discs of $T$. harzianum were set on the periphery of the petridish surrounding one disc of $\mathrm{MoO}$ on the center of the petridish, 3 $=$ Four discs of $T$. harzianum were set on the periphery of the petridish surrounding one disc of $\mathrm{MoO}$ on the center of the petridish, $4=$ Three discs of MoO were set on the periphery of the petridish surrounding one disc of $T$. harzianum on the center of the petridish, $5=$ Four discs of $M$. oryzaeoryzae were set on the periphery of the petridish surrounding one disc of $T$. harzianumon the center of the petridish and $6=$ Control plates of $M$. oryzae oryzae and $7=$ Control plates of $T$. harzianum THR 4. 
$4.67 \mathrm{~mm}$ whereas the mycelia growth of bio-agent towards $\mathrm{MoO}$ was $35.33 \mathrm{~mm}$ followed by fifth design where mycelila radial growth of $\mathrm{MoO}$ was towards $T$. harzianum was $5 \mathrm{~mm}$ whereas mycelia radial growth of $T$. harzianum towards $\mathrm{MoO}$ was recorded $35 \mathrm{~mm}$ and in first design where mycelia radial growth of MoO was towards $T$. harzianum was $8.33 \mathrm{~mm}$ whereas mycelia radial growth of T. harzianum towards $\mathrm{MoO}$ was recorded $28.33 \mathrm{~mm}$. In control condition mycelia radial growth of tested fungus and bio-agent was $25 \mathrm{~mm}$ and $40 \mathrm{~mm}$ respectively.

In vitro condition third design where four discs of $T$. harzianum were set on the periphery of the petridish surrounding one disc of $\mathrm{MoO}$ on the center of the petridish following dual culture technique gave most satisfactory result.

\section{Discussions}

Trichoderma species have been investigated as biological control agents over 70 years [20]. In our study all five designs of in vitro studies shown reduced growth of $\mathrm{MoO}$ compared to control plates. Among the five designs of our experiment the third design where four discs of $T$. harzianum was set on the periphery of the petridish surrounding one disc of $\mathrm{MoO}$ on the center of the petridish in dual culture technique gave most satisfactory result in both cases of mean mycelium growth inhibition and interactions with MoO. In a previous study the highest percentage inhibition of radial growth (PIRG) values was observed with T. harzianum IMI-392432 using two dual culture methods, $63.80 \%$ in Method I and $80.82 \%$ in Method II [21]. In the first method (Method-I), an agar disc (6 mm) was taken from 4-day-old PDA culture plates of each Trichoderma isolate and placed at the periphery of the PDA plates $(9 \mathrm{~mm})$. Another agar disc of the same size of $C$. paradoxa was also placed at the periphery but on the opposing end of the same Petri dish. In the second method (Method-II), an agar disc (6-mm) of the antagonist, Trichoderma (T), was placed $2 \mathrm{~cm}$ away from the periphery of the Petri dish, and a same sized agar disc of the test fungus, $C$. paradoxa (C), was similarly placed $2 \mathrm{~cm}$ away from the edge of the Petri plate but on the end opposite of Trichoderma sample. As a control, $C$. paradoxa was placed in a similar manner on a fresh PDA plate. They also used poison agar, and direct methods to assess the ability of Trichoderma virens IMI-392430, T. pseudokoningii IMI392431, T. harzianum IMI-392432, T. harzianum IMI-392433, and T. harzianum IMI-392434 to control $C$. paradoxa, which causes the pineapple disease of sugarcane. In another study it had been observed that Trichoderma sp. isolated from soil and tested in vitro against soil borne pathogens viz. Sclerotium rolfsii, Rhizoctonia solani, Sclerotinia sclerotium and Fusarium solani using dual culture technique and $100 \%$ growth inhibition was found in case of Sclerotium rolfsii [22]. T. viride (MO) also reduced the colony area of Macrophomina phaseoli by 19.2 and $34.9 \%$ using the dual culture and cellophane methods, respectively reported in other study [23].

Trichoderma viride was evaluated under laboratory conditions against some 
common phyto-pathogens belonging to different groups of fungi, effectively inhibited the growth of the tested pathogens in dual cultures by hyperparasitism and by secretion of volatile and non-volatile metabolites. In the dual culture experiment, maximum inhibition was recorded for Fusarium oxysporum followed by Rhizoctonia solani and least for Alternaria zinnia [24]. Other than mycelia interaction and hyperparasitism by the Trichoderma species, scientists have also considered the action use of antibiotic metabolites as a contributing mechanism in the biocontrol of plant pathogens [25].

Volatile and non-volatile compounds of Trichoderma spp. were analyzed by GC-MS technique and the properties of distinguished compounds showed antifungal, antimicrobial and antibiotic activities [26]. Volatile compounds of $T$. harzianum and $T$. viride showed highest percent abundance for glacial acetic acid $(45.32 \%)$ and propyl-benzene $(41.75 \%)$, respectively. In case of non-volatile compounds, T. harzianum and T. viride showed D-Glucose, 6-O- $\alpha-\mathrm{D}$-galactopyranosyl (38.45\%) and 17-Octadecynoic acid (36.23\%), respectively. The results of present study confirmed that T. harzianum can be used as a promising biological control agent.

Our results are in accordance to those reported by [27] who agreed to the statement that antagonistic such as T. harzianum gave $70 \%$ 88\% mycelia and conidial inhibition of $M$. oryzae. Similarly, an interaction study different species of Trichoderma against 24 airborne plant pathogens including $M$. oryzae were studied where T. hamatum, T. harzianum, T. koningii, T. pseudokoningii and T. viride were found to have strong antagonistic potential. He also found that selective isolates of T. harzianum and T. viride showed severe antagonism against $M$. oryzae, while T. polysporum was weaker antagonist [28]. Most of the antagonistic fungi were effectively inhibited the spore production of the plant pathogens where the growth inhibition (GI) of the spore production were greatly increased in some of the antagonistic fungi used [29]. This was happened due to the activity of enzymes produced by the antagonistic fungi such as Trichoderma sp. and Penicillium sp. The isolate T39 of Trichoderma harzianum which can be regarded as a model to demonstrate biocontrol under commercial conditions and the mechanisms involved [30].

\section{Conclusion}

Five different designs of dual culture technique were used to know the interactions between Magnaporthe oryzae oryzae (MoO) and T. harzianum THR 4. In in vitro condition third design where four discs of $T$. harzianum were set on the periphery of the petridish surrounding one disc of $\mathrm{MoO}$ on the center of the petridish in dual culture technique gave most satisfactory result with $92 \%$ growth inhibition of MoO. All the designs of dual culture were effective in vitro test against the test fungus Magnaporthe oryzae oryzae.

\section{Acknowledgements}

We thank anonymous reviewers for their kind review of the manuscript. This 
research was financially supported by Sher-e-Bangla Agricultural University Research System (SAURES), Project ID:

SAU/SAURES/Project/2018-19/4829/1505(13).

\section{Competing Interests}

Authors have declared that no competing interests exist.

\section{Authors' Contributions}

This work was carried out in collaboration among all authors. Author ZN conducted the research work. Author FMA designed and supervised the study and edited the manuscript. Author LL and MLA managed the literature searches. All authors read and approved the final manuscript.

\section{References}

[1] Tobias, A., Molina, I., Valera, H.G., Mottaleb, K.A. and Mohanty, S. (2012) Handbook on Rice Policy for Asia. International Rice Research Institute, Los Baños.

[2] Timothy, S.T., Khandaker, M., Catherine, C., Anwarul, H., Nazria, I., Saad, Q. and Yan, S. (2013) Agriculture and Adaptation in Bangladesh: Current and Projected Impacts of Climate Change. Discussion Paper, IFPRI (International Food Policy Research Institute), Wshington DC, No. 01281, 76.

[3] Nalley, L., Tsiboe, F., Durand-Morat, A., Shew, A. and Thoma, G. (2016) Economic and Environmental Impact of Rice Blast Pathogen (Magnaporthe oryzae) Alleviation in the United States. PLoS ONE, 11, Article ID: e0167295. https://doi.org/10.1371/journal.pone.0167295

[4] Rayhanul, M.I., Aminuzzaman, F.M., Chowdhury, M.S.M., Laila, L. and Ahmed, M. (2019) Survey on Rice Blast in Some Selected area of Bangladesh and in Vitro Evaluation of Fungicides against Pyricularia oryzae. Bangladesh Journal of Plant Patholo$g y, 35,59-64$.

[5] Oh, Y.Y. (2008) Genome-Wide Transcription Studies on Infection Structure Formation and Function in Magnaporthe grisea. Ph.D. Dissertation, North Carolina State University, Raleigh, 142.

[6] Anwar, A., Bhat, G.N. and Singhara, G.S. (2002) Management of Sheath Blight and Blast in Rice through Seed Treatment. Annals of Plant Protection Sciences, 10, 285 287.

[7] Gohel, N.M., Chauhan, H.L. and Mehta, A.N. (2008) Bio-Efficacy of Fungicides against Pyricularia oryzae the Incitant of Rice Blast. Journal of Plant Disease Sciences, 3, 189-192.

[8] Iftikhar, T., Babar, L.K., Zahoor, S. and Khan, N.G. (2010) Best Irrigation Management Practices in Cotton. Pakistan Journal of Botany, 42, 3023-3028.

[9] Babar, L.K., Iftikhar, T., Khan, H. and Makhdum, A.H. (2011) Agronomic Trials on Sugarcane Crop under Faisalabad Conditions. Pakistan Journal of Botany, 43, 929 935.

[10] Nazifa, Z., Aminuzzaman, F.M., Laila, L. and Rehena, M.K. (2021) In Vitro Efficacy of Botanicals against Rice Blast Pathogen Magnaporthe oryzae oryzae. American Journal of Plant Sciences, 12, 662-678. https://doi.org/10.4236/ajps.2021.124045

[11] Mukherjee, P.K., Nautiyal, C.S. and Mukhopadhyay, A.N. (2008) Molecular Mechan- 
isms of Biocontrol by Trichoderma spp. In: Nautiyal, C.S. and Dion, P., Eds., Molecular Mechanisms of Plant and Microbe Coexistence, Vol. 15, Springer, Berlin, Heidelberg, 243-262. https://doi.org/10.1007/978-3-540-75575-3 10

[12] Ouazzani, T.A., Mouria, A., Douira, A., Benkirane, R., Mlaiki, A. and El-Yachioui, M. (1998) In Vitro Effect of $\mathrm{pH}$ and Temperature on the Ability of Trichoderma spp., to Reduce the Growth of Pyricularia oryzae. Journal of CAB Direct, 96, 19-24.

[13] Burges, H.D. and Jones, K.A. (1998) Trends in Formulation of Microorganisms and Future Research Requirements. In: Burges, H.D., Ed., Formulation of Microbial Biopesticides, Kluwer Academic Publishers, Dordrecht, 311-332. https://doi.org/10.1007/978-94-011-4926-6 10

[14] Whipps, J.M. (2001) Microbial Interactions and Biocontrol in the Rhizosphere. Journal of Experimental Botany, 52, 487-511.

https://doi.org/10.1093/jxb/52.suppl 1.487

[15] Harman, G.E. (2000) Myths and Dogmas of Biocontrol Changes in Perceptions Derived from Research on Trichoderma harzianum T-22. Plant Disease, 84, 377-393. https://doi.org/10.1094/PDIS.2000.84.4.377

[16] Sparkman, O.D., Penton, Z. and Kitson, F.G. (2011) Gas Chromatography and Mass Spectrometry: A Practical Guide. 2nd Edition, Academic Press, Cambridge. https://doi.org/10.1016/C2009-0-17039-3

[17] Nazifa, Z., Aminuzzaman, F.M., Akhter, K., Rehena, M.K. and Laila, L. (2021) Survey on Rice Blast and Morphological Characterization of Magnaporthe oryzae oryzae. Journal of Advances in Microbiology, 21, 8-21. https://doi.org/10.9734/jamb/2021/v21i130315

[18] Aminuzzaman, F.M., Jahan, S.N., Shammi, J., Mitu, A.I. and Liu, X.Z. (2018) Isolation and Screening of Fungi Associated with Eggs and Females of Root-Knot Nematodes and Their Biocontrol Potential against Meloidogyne incognita in Bangladesh. Archives of Phytopathology and Plant Protection, 51, 288-308. https://doi.org/10.1080/03235408.2018.1472359

[19] Yaqub, F. and Shahzad, S. (2005) In-Vitro Evaluation of Microbial Antagonists against Sclerotium rolfsii. Pakistan Journal of Botany, 37, 1033-1036.

[20] Samuels, G.J. (1996) Trichoderma: A Review of Biology and Systematics of the Genus. Mycological Research, 100, 923-935. https://doi.org/10.1016/S0953-7562(96)80043-8

[21] Rahman, M.A., Begum, M.F. and Alam, M.F. (2009) Screening of Trichoderma Isolates as a Biological Control Agent against Ceratocystis paradoxa Causing Pineapple Disease of Sugarcane. Mycobiology, 37, 277-285. https://doi.org/10.4489/MYCO.2009.37.4.277

[22] Bastakoti, S., Belbase, S., Manandhar, S. and Arjyal, C. (2017) Trichoderma Species as Biocontrol Agent against Soil Borne Fungal Pathogens. Nepal Journal of Biotechnology, 5, 39-45.

[23] Etabarian, H.R. (2006) Evaluation of Trichoderma Isolates for Biological Control of Charcoal Stem Rot in Melon Caused by Macrophomina phaseolina. Journal of Agricultural Science Technology, 8, 243-250.

[24] Tapwal, A., Singh, U., Singh, G., Garg, S. and Kumar, R. (2011) In Vitro Antagonism of Trichoderma viride against Five Phytopathogens. Pest Technology, 5, 59-62.

[25] Ghisalberti, E.L. and Rowland, C.Y. (1993) Antifungal Metabolites from Trichoderma harzianum. Journal of Natural Products, 56, 1799-1804.

https://doi.org/10.1021/np50100a020 
[26] Mukesh, M., Prashant, S. andleeb, Z., Manish, K.D. and Upadhyay, R.S. (2017) Antagonistic Assessment of Trichoderma spp. by Producing Volatile and Non-Volatile Compounds against Different Fungal Pathogens. Archives of Phytopathology and Plant Protection, 50, 629-648. https://doi.org/10.1080/03235408.2017.1357360

[27] Gouramanis, G.D. (1995) Biological and Chemical Control of Rice Blast Disease (Pyricularia oryzae) in North Greece. Cahiers Options Méditerranéennes, 15, 61-68.

[28] Watanabe, N. (1985) Antagonism by Various Kinds of Trichoderma Fungi to Airborne Plant Pathogens. Bulletin of the Faculty of Agriculture-Meiji University, 68, $1-9$.

[29] Srinon, W., Chuncheen, K., Jirattiwarutkul, K., Soytong, K. and Kanokmedhakul, S. (2006) Efficacies of Antagonistic Fungi against Fusarium Wilt Disease of Cucumber and Tomato and the Assay of Its Enzyme Activity. Journal of Agricultural Technology, 2, 191-201.

[30] Elad, Y. (2000) Biological Control of Foliar Pathogens by Means of T. harzianum and Potential Modes of Action. Crop Protection, 19, 709-714.

https://doi.org/10.1016/S0261-2194(00)00094-6 